Research Paper

\title{
Monocytosis as a prognostic factor for survival in stage IB and IIA cervical cancer
}

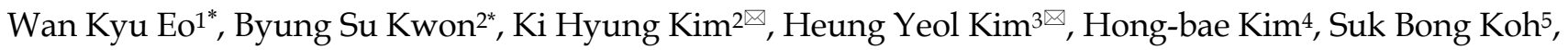 \\ Sungwook Chun ${ }^{6}$, Yong Il Ji ${ }^{6}$, Ji Young Lee", Jeong Namkung ${ }^{8}$,Sanghoon Kwon ${ }^{9}$ \\ 1. Department of Internal Medicine, College of Medicine, Kyung Hee University, Seoul, Korea. \\ 2. Department of Obstetrics and Gynecology, Pusan National University School of Medicine; Biomedical Research Institute, Pusan National University \\ Hospital, Busan, Korea. \\ 3. Department of Obstetrics and Gynecology, College of Medicine, Kosin University, Busan, Korea. \\ 4. Department of Obstetrics and Gynecology, Kangnam Sacred Heart Hospital, Hallym University Medical Center, Hallym University College of Medicine, \\ Seoul, Korea. \\ 5. Department of Obstetrics and Gynecology, Catholic University of Daegu, School of Medicine, Daegu, Korea. \\ 6. Department of Obstetrics and Gynecology, College of Medicine, Inje University, Busan, Korea. \\ 7. Department of Obstetrics and Gynecology, Research Institute of Medical Science, Konkuk University School of Medicine, Seoul, Korea. \\ 8. Department of Obstetrics and Gynecology, Catholic University, Seoul, Republic of Korea. \\ 9. Department of Obstetrics and Gynecology, Keimyung University, School of Medicine, Daegu, Korea \\ *Eo WK and Kwon BS equally contributed to this article for first author.
}

$\square$ Corresponding authors: Ki Hyung Kim, M.D., Ph.D., Department of Obstetrics and Gynecology, Pusan National University School of Medicine; Biomedical Research Institute, Pusan National University Hospital, Busan 602-739, Korea; Phone: +82-51-990-6226; Fax: +82-51-990-3300; e-mail: kihyungkimpnu@gmail.com and Heung Yeol Kim, M.D., Ph.D., Department of Obstetrics and Gynecology, Kosin University College of Medicine, 34, Amnam-dong, Seo-gu, Busan 602-702, Korea; Phone: +82-51-990-3088; Fax: +82-51-241-5458; E-mail: hykyale@yahoo.com

(C) Ivyspring International Publisher. This is an open access article distributed under the terms of the Creative Commons Attribution (CC BY-NC) license (https://creativecommons.org/licenses/by-nc/4.0/). See http://ivyspring.com/terms for full terms and conditions.

Received: 2017.08.04; Accepted: 2017.10.18; Published: 2018.01.01

\begin{abstract}
Objective: To measure hematologic parameters derived from the white blood cell (WBC) count and differential count (DC) as prognostic factors for survival in patients with stage IB and IIA cervical cancer.

Methods: We retrospectively examined demographic, clinicopathologic, and laboratory parameters in a cohort of 233 patients with International Federation of Gynecology and Obstetrics stage IB and IIA cervical cancer who underwent surgical resection. We further assessed the effects of the WBC count and DC-derived hematologic parameters on progression-free survival (PFS) and overall survival (OS) after controlling for other parameters.

Results: Patients were followed up for a median of 46.6 months (range, 9-142 months). The Kaplan-Meier estimates of PFS and OS at 5 years were $88.5 \%$ and $92.3 \%$, respectively. In a multivariate analysis, we identified the absolute monocyte count (AMC) (hazard ratio $[H R], 11.78 ; P<0.001$ ) and tumor size $(H R, 5.41 ; P=0.003)$ as the strongest prognostic factors affecting PFS. We also identified AMC (HR, 23.29; $P<0.001)$, tumor size, (HR, 5.27; $P=0.033)$, and lymph node involvement (HR, 3.90; $P=$ 0.027 ) as the strongest prognostic factors affecting OS. AMC remained prognostic with respect to PFS or OS in a Cox model that controlled for the neutrophil-lymphocyte ratio or lymphocyte-monocyte ratio, although neither ratio was a significant prognostic factor for survival.

Conclusions: Monocytosis and an increased tumor size were found to be independent prognostic factors affecting both PFS and OS in patients with stage IB and IIA cervical cancer.
\end{abstract}

Key words: Monocytes, Uterine cervical neoplasms

\section{Introduction}

Cervical cancer was the fourth-most common type of cancer and the leading cause of cancer death worldwide in 2012, with an estimated 530000 new cases. In addition, more than $84 \%$ of new cases occurred in developing countries [1]. Despite the substantially lower cervical cancer incidence in developed countries, the American Cancer Society estimated that 12990 women in the United States 
would be diagnosed with cervical cancer and an estimated 4120 women would die from this disease in 2016 [2].

Regular Papanicolaou test screening is essential, given the relatively high incidence and poor survival rate of this cancer, and the establishment of prognosticators predictive of the risks of relapse, progression, or death could lead to individualized therapies and improvements in clinical outcomes. Regarding clinicopathologic prognostic factors, the histologic classification [3-7], histologic grade [4], tumor size, lymph nodes (LN) metastasis [3, 4, 6, 8-10], lymphovascular space (LVS) invasion [3, 4], squamous cell carcinoma antigen [9], and various molecular markers [4, 9] have been reported as potential predictors of survival.

Recently, hematologic parameters derived from the white blood cell (WBC) count and differential count (DC) have been described as prognostic factors in various kinds of cancers. In cervical cancer, the WBC count [11, 12], absolute neutrophil count (ANC) [13], absolute lymphocyte count (ALC) [13], and absolute monocyte count (AMC) [7, 13] have been reported as prognostic factors for survival. In addition, the neutrophil-lymphocyte ratio (NLR) [10, 11, 14-16] and lymphocyte-monocyte ratio (LMR) [7, 8] were found to be significant prognostic parameters for survival.

Regarding hematologic parameters, however, only a few studies of early-stage cervical cancer have been published, and their results require validation in another patient cohort. In this study, we aimed to assess the hematologic parameters as predictors of survival in patients with International Federation of Gynecology and Obstetrics (FIGO) stage IB and IIA cervical cancer.

\section{Materials and Methods}

We retrospectively evaluated patients with FIGO stage IB and IIA cervical cancer who underwent hysterectomy procedures at university hospitals between October 2005 and December 2013. Patients were excluded from this study if any of the following conditions applied: coexisting cancers, history of cancer during the previous 5 years, autoimmune disease, infection, or recent blood product transfusion. In addition, patients with histologic tumor types other than squamous cell carcinoma, adenocarcinoma, or adenosquamous carcinoma were not included. Patients who had received cancer treatments, including radiotherapy or chemotherapy before hysterectomy were also excluded. Finally, patients taking specific medications such as corticosteroids, non-steroidal anti-inflammatory drugs, or recombinant granulocyte colony- stimulating factor were excluded. The data collection and analysis methods were approved by the institutional review board, and the study was conducted in accordance with the detailed enforcement regulations of Korea and the principles of the Declaration of Helsinki.

Data, including patient demographic information such as age and body mass index (BMI), were obtained from medical records. Data for clinicopathologic features, including histologic type, histologic grade, FIGO stage, tumor size, LN invasion, LVS invasion, and status or resection margin, were also collected for analysis. Histologic typing was based on the World Health Organization classification, and was subjected to peer review by a single pathologist to improve consistency. Laboratory measurements conducted routinely prior to surgical resection were selected for analysis. Hematologic parameters included the WBC count, ANC, ALC, and $\mathrm{AMC}$, hemoglobin concentration, and platelet count. All parameters were measured using samples collected via venipuncture into ethylenediamine tetraacetic acid-containing tubes, and data were obtained within 1 hour after collection to avoid possible morphological changes. If numerous laboratory results were available, preoperative findings collected nearest to the surgical date were selected for analysis.

All patients with cervical cancer underwent a radical hysterectomy, bilateral salpingo-oophorectomy, and pelvic LN dissection [17]. Women with positive and/or close margins after resection or positive LNs were considered to be at high risk for recurrence and received adjuvant therapy [18].

Survival curves were created using the Kaplan-Meier method and were compared using the log-rank test. Progression-free survival (PFS) was defined as the interval from the date of hysterectomy until progression or death, whichever occurred first, or until the patient was censored at the time of the last follow-up if no progression or death occurred. Overall survival (OS) was defined as the interval from date of hysterectomy until death or censoring at the time of the last follow-up if the patient remained alive.

Univariate analyses of demographic, clinicopathologic, and laboratory parameters were performed using a Cox proportional hazards model to identify independent factors for survival. The variables included BMI, age, histologic type, histologic grade, FIGO stage, tumor size, LN involvement, LVS invasion, resection margin status, WBC count, ANC, ALC, AMC, hemoglobin concentration, and platelet count. Continuous variables, including BMI, age, WBC count, ANC, ALC, AMC, hemoglobin concentration, and platelet 
count, were dichotomized according to well-validated cut-off points, rather than the median or a receiver-operating characteristic (ROC) curve analysis, to obtain more practical and easily reproducible results. Regarding the WBC count and DC, we defined leukocytosis as a WBC count $>11000 / \mu \mathrm{L}[19,20]$, neutrophilia as an ANC $>7700 / \mu \mathrm{L}$ [20, 21], lymphocytopenia as an ALC $<1000 / \mu \mathrm{L}$ [22], and monocytosis as an AMC $>800 / \mu \mathrm{L}$ [23]. Tumor size was dichotomized based on an ROC curve analysis. For PFS, the optimal cut-off for tumor size was $2.6 \mathrm{~cm}$ (area under curve [AUC] $=0.636, P=$ 0.009 ) with a sensitivity of $81.82 \%$ and specificity of $51.18 \%$; for OS, the corresponding value was $2.6 \mathrm{~cm}$ $(\mathrm{AUC}=0.673, P=0.007)$, with a sensitivity of $85.71 \%$ and specificity of $50.23 \%$. For the multivariate analysis, variables with $P$ values $<0.05$ in the univariate analysis were included in a Cox proportional hazards model. Hazard ratios (HRs) with corresponding 95\% confidence intervals (CIs) were estimated. We also assessed correlations of the hematologic variables that were identified as significant in the current study with demographic and laboratory variables.

All presented $P$ values are two-sided, and statistical significance was defined as a $P$ value $<0.05$. Statistical analyses were conducted using SPSS statistical software, version 18.0 (SPSS Inc., Chicago, IL, USA).

\section{Results}

A total of 346 consecutive patients with histologically confirmed cervical cancer who underwent hysterectomy were reviewed, and 233 patients were enrolled after screening (Figure 1). The patients' baseline demographic and clinicopathologic characteristics are displayed in Table 1 . The median age was 51 years, and the median BMI was 23.2 $\mathrm{kg} / \mathrm{m}^{2}$. Among enrolled patients, 165 (70.8\%), 33
(14.2\%), 18 (7.7\%), and 17 (7.3\%) had FIGO stage IB1, IB2, IIA1, and IIA2 disease, respectively. Squamous cell carcinoma was the most common histological type $(77.7 \%)$, followed by adenocarcinoma (18.0\%) and adenosquamous carcinoma (4.3\%). Grade 2 was the most frequent histological grade $(49.1 \%)$. The median primary tumor size was $2.7 \mathrm{~cm}$. The patients' baseline hematologic parameters are also displayed in Table 1. The median peripheral blood WBC count, ANC, ALC and AMC were $6490 / \mu \mathrm{L}, 3866.1 / \mu \mathrm{L}$, $1870.2 / \mu \mathrm{L}$ and $379.3 / \mu \mathrm{L}$, respectively. In addition, the median hemoglobin concentration was $12.9 \mathrm{~g} / \mathrm{dL}$, and the median platelet count was $260000 / \mu \mathrm{L}$.

Patients were followed up for a median of 46.6 months (range, 9-142 months). The Kaplan-Meier estimates of 5-year PFS and OS rates in the general cohort were $88.5 \%$ and $92.3 \%$, respectively. Notably, the 5-year PFS rates differed significantly with respect to the WBC count and AMC. Similarly, the 5-year OS rates differed significantly according to $\mathrm{WBC}, \mathrm{ANC}$, and AMC. However, no significant differences in 5 -year PFS and OS rates related to ALC were observed (Table 2).

Through a univariate analysis in which hematologic parameters were included as continuous variables in a Cox proportional hazards model, the WBC count (HR, 1.0002; 95\% CI: 1.0001-1.0004; $P=$ 0.008 ), ANC (HR, 1.0002; 95\% CI: 1.0000-1.0004; $P=$ 0.039 ), and AMC (HR, 1.0029; 95\% CI: 1.0005-1.0042; $P$ $=0.012$ ) were found to associate significantly with PFS. In addition, a univariate analysis that included hematologic parameters as discrete variables identified five significant risk factors for PFS: WBC, AMC, age, tumor size, and histologic grade. In a multivariate analysis, AMC (HR, 11.78; 95\% CI: 3.43-40.49; $P<0.001)$ and tumor size (HR, 5.41; 95\% CI: $1.81-16.15 ; P=0.003)$ were identified as the strongest prognostic factors affecting PFS (Table 3 ).

Regarding OS, a univariate, Cox proportional hazards model-based analysis of WBC count and DC-derived hematologic parameters (continuous variables) identified WBC count (HR, 1.0002; 95\% CI: 1.0000-1.0004; $P=0.018)$, ANC (HR, 1.0003; 95\% CI: 1.0001-1.0005; $P=0.013)$, and AMC (HR, 1.0030; 95\% CI: $1.0010-1.0051 ; P=0.004)$ as significantly associated with OS. In addition, a Cox proportional hazards model-based univariate analysis that included dichotomized variables identified seven significant risk factors for OS: WBC count, ANC, AMC, age, 
stage, tumor size, and LN involvement. In a multivariate analysis, we identified AMC (HR, 23.29; 95\% CI: 5.40-100.38; $P<0.001)$, tumor size (HR, 5.27; 95\% CI: 1.15-24.23; $P=0.033$ ), and $\mathrm{LN}$ involvement (HR, 3.90; 95\% CI: 1.17-12.96; $P=0.027$ ) as the strongest prognostic factors affecting OS (Table 4). The independent prognostic value of AMC with respect to PFS and OS was also maintained in a Cox proportional hazards model (data not shown) that controlled for NLR or LMR as specific variables; neither NLR nor LMR was a significant prognostic factor affecting PFS or OS in a multivariate analysis. In addition, significant correlations of the AMC were observed with the WBC count $(r=0.590, P<0.001)$, ANC $(r=0.451, P<0.001)$, and ALC $(r=0.274, P$ $<0.001)$; however, AMC did not correlate significantly with BMI, age, tumor size, hemoglobin concentration, or platelet count.

Table 1. Demographic, clinicopathologic, and laboratory characteristics of 233 patients with cervical cancer.

\begin{tabular}{|c|c|}
\hline Characteristics & Median (IQR) \\
\hline BMI $\left(\mathrm{kg} / \mathrm{m}^{2}\right)$ & $23.2(3.8)$ \\
\hline Age (years) & $51(15.0)$ \\
\hline \multicolumn{2}{|l|}{ Histology, $n(\%)$} \\
\hline Squamous cell carcinoma & $181(77.7 \%)$ \\
\hline Adenocarcinoma & $42(18.0 \%)$ \\
\hline Adenosquamous carcinoma & $10(4.3 \%)$ \\
\hline \multicolumn{2}{|l|}{ Histologic grade, $n(\%)$} \\
\hline 1 & $87(37.5 \%)$ \\
\hline $2-3$ & $145(62.5 \%)$ \\
\hline \multicolumn{2}{|l|}{ Stage (FIGO), $n(\%)$} \\
\hline IB1 & $165(70.8 \%)$ \\
\hline IB2-IIA & $68(29.2 \%)$ \\
\hline Size of tumor $(\mathrm{cm})$ & $2.7(2.5)$ \\
\hline \multicolumn{2}{|l|}{$\mathrm{LN}$ invasion, $n(\%)$} \\
\hline Negative & $189(81.1 \%)$ \\
\hline Positive & $44(18.9 \%)$ \\
\hline \multicolumn{2}{|l|}{ LVS invasion, $n(\%)$} \\
\hline Negative & $164(70.4 \%)$ \\
\hline Positive & $69(29.6 \%)$ \\
\hline \multicolumn{2}{|l|}{ RM involvement, $n(\%)$} \\
\hline Negative & $225(96.6 \%)$ \\
\hline Positive & $8(3.4 \%)$ \\
\hline WBC count (per $\mu \mathrm{L}$ ) & $6490.0(2330.0)$ \\
\hline ANC (per $\mu \mathrm{L})$ & $3866.1(1848.9)$ \\
\hline $\operatorname{ALC}($ per $\mu \mathrm{L})$ & $1870.2(890.3)$ \\
\hline $\mathrm{AMC}($ per $\mu \mathrm{L})$ & $379.3(200.0)$ \\
\hline Hemoglobin $(\mathrm{g} / \mathrm{dL})$ & $12.9(1.7)$ \\
\hline Platelet count $\left(\times 10^{3}\right.$ per $\left.\mu \mathrm{L}\right)$ & $260.0(90.0)$ \\
\hline
\end{tabular}

IQR, interquartile range; SD, standard deviation; BMI, body mass index; FIGO, International Federation of Gynecology and Obstetrics; LN, lymph node; LVS, lymphovascular space; RM, resection margin; WBC, white blood cell; ANC, absolute neutrophil count; ALC, absolute lymphocyte count; AMC, absolute monocyte count; AEC, absolute eosinophil count; NLR, neutrophil-lymphocyte ratio; LMR, lymphocyte-monocyte ratio.

In our study, we identified AMC as a significant predictor of both PFS $(P<0.0001)$ and OS $(P<0.0001)$ among patients with stage IB and IIA diseases. This result was not consistent with a previous report by Lee et al [13]. In that report, AMC was not found to be significantly predictive of PFS or OS in a multivariate analysis limited to stages IB and IIA, and ANC was the only valuable prognostic hematologic parameter for OS $(P=0.022)$ [13]. Differences in the methods used to determine cut-off values might account for the discrepancies in these results. Lee et al. used medians to determine cut-off values for hematologic variables. In contrast, in the current study, we used well-determined cut-off values, rather than median values, to obtain more reproducible results. In our validation experiment using the cut-off value of $328 / \mu \mathrm{L}$ from a previous study [13], AMC was not found to be a significant factor affecting PFS and OS in a multivariate analysis (data not shown); similarly, ANC (cut-off value of $3479 / \mu \mathrm{L}$ ) was identified as a significant prognosticator for PFS or OS by multivariate analysis (data not shown). We conclude that utilizing well-determined cut-off values, rather than median values, might better predict PFS and OS in patients with stage IB and IIA diseases. Although the prognostic value of AMC for more advanced-stage disease (e.g., stages IIB-IV) was not the scope of the current study, the literature suggests that consensus has also not been reached regarding this issue. Lee et al. previously reported the significance of AMC (cut-off value: 408.5/ $\mu \mathrm{L}$ ), determined using median values, as a prognostic factor for PFS $(P=0.007)$ and OS $(P=0.038)$ in stage IIB-IVA disease [13]. On the other hand, $\mathrm{Li}$ et al. found that AMC (cut-off value: $380 / \mu \mathrm{L}$ ) was not a significant prognosticator for PFS or OS in stage IIA-IVA disease (stage IIB-IVA disease comprised $79.72 \%$ of total) in a multivariate analysis following a ROC curve analysis [7]. Additional studies are therefore required to validate the role of $\mathrm{AMC}$ in both early- and advanced-stage cervical cancers.

Recently, hematologic parameters such as the NLR and LMR have been widely investigated as useful prognostic markers in cancers. For example, the NLR has previously been reported as a prognosticator of survival in cervical cancer [10, 11, 14-16]. However, we did not identify the NLR (cut-off values: 2.47 for PFS and 2.71 for OS, ROC curve analysis) as a significant prognosticator for PFS or OS in a multivariate analysis. In a study by Chen et al., the NLR (cut-off values: 2.42 for recurrence-free survival [RFS] and 2.09 for OS, ROC curve analysis) was identified as an independent risk factor for RFS ( $P$ $=0.002)$ and OS $(P=0.009)$ through a multivariate analysis restricted, as in our study, to patients with stage IB and IIA disease [16]. To evaluate this inter-study discrepancy, we dichotomized the NLR using the cutoff determined by Chen et al [16]. However, the NLR did not remain a surrogate marker of PFS or OS (data not shown) in a multivariate 
analysis.

The LMR was also suggested to associate with survival among patients with cervical cancers $[7,8]$. In another study by Chen et al. that, like our study, included only patients with stage IB and IIA disease, the LMR (cut-off value: 2.87 for both RFS and OS, ROC curve analysis) was a significant prognostic marker for RFS $(P<0.001)$ and OS $(P=0.001)$ [8]. However, in our study, the LMR (cut-off values: 4.89 for PFS and 6.64 for OS; ROC curve analysis) was not a surrogate marker for either PFS or OS in a multivariate analysis (data not shown). We further validated the cutoff value of 2.87 from a previous study [8] in our cohort, but failed to identify LMR as a significant prognosticator for PFS or OS in a multivariate analysis (data not shown).

Table 2. Kaplan-Meier estimates of progression-free survival (PFS) and overall survival (OS) in each subgroup and corresponding $P$-values.

\begin{tabular}{|c|c|c|c|c|c|}
\hline Characteristics & Categories & $\begin{array}{l}5 \text {-year } \\
\text { PFS (\%) }\end{array}$ & $P$-value & $\begin{array}{l}\text { 5-year } \\
\text { OS (\%) }\end{array}$ & $P$-value \\
\hline \multirow[t]{2}{*}{ BMI $\left(\mathrm{kg} / \mathrm{m}^{2}\right)$} & $\leq 25$ & 90.1 & 0.081 & 93.4 & 0.245 \\
\hline & $>25$ & 81.3 & & 89.4 & \\
\hline \multirow[t]{2}{*}{ Age (years) } & $\leq 65$ & 95.1 & 0.038 & 94.1 & 0.008 \\
\hline & $>65$ & 80.2 & & 81.4 & \\
\hline \multirow[t]{2}{*}{ Histology, $n(\%)$} & Squamous & 89.2 & 0.323 & 93.0 & 0.687 \\
\hline & Non-squamous & 86.4 & & 90.3 & \\
\hline \multirow{2}{*}{$\begin{array}{l}\text { Histologic } \\
\text { grade, } n(\%)\end{array}$} & 1 & 93.1 & 0.034 & 95.8 & 0.052 \\
\hline & $2-3$ & 90.0 & & 89.7 & \\
\hline \multirow[t]{2}{*}{ Stage (FIGO) } & IB1 & 90.7 & 0.053 & 95.0 & 0.008 \\
\hline & IB2-IIA & 83.3 & & 86.0 & \\
\hline \multirow{2}{*}{$\begin{array}{l}\text { Size of tumor } \\
(\mathrm{cm})\end{array}$} & $\leq 2.6$ & 93.9 & 0.001 & 96.6 & 0.006 \\
\hline & $>2.6$ & 83.4 & & 88.2 & \\
\hline \multirow[t]{2}{*}{ LN invasion } & Negative & 89.9 & 0.276 & 93.9 & 0.014 \\
\hline & Positive & 82.0 & & 85.4 & \\
\hline \multirow[t]{2}{*}{ LVS invasion } & Negative & 89.1 & 0.599 & 92.4 & 0.768 \\
\hline & Positive & 87.2 & & 92.1 & \\
\hline \multirow[t]{2}{*}{ RM involvement } & Negative & 89.1 & 0.155 & 92.8 & 0.570 \\
\hline & Positive & 70.0 & & 83.3 & \\
\hline \multirow[t]{2}{*}{ WBC (per $\mu \mathrm{L}$ ) } & $\leq 11000$ & 90.1 & 0.002 & 94.3 & $<0.001$ \\
\hline & $>11000$ & 50.0 & & 45.7 & \\
\hline \multirow[t]{2}{*}{ ANC (per $\mu \mathrm{L})$} & $\leq 7700$ & 89.6 & 0.090 & 93.8 & 0.014 \\
\hline & $>7700$ & 43.8 & & 40.0 & \\
\hline \multirow[t]{2}{*}{$\mathrm{ALC}($ per $\mu \mathrm{L})$} & $<1000$ & 89.5 & 0.410 & 93.7 & 0.068 \\
\hline & $\geq 1000$ & 77.8 & & 77.8 & \\
\hline \multirow[t]{2}{*}{$\mathrm{AMC}($ per $\mu \mathrm{L})$} & $\leq 800$ & 90.2 & $<0.001$ & 94.3 & $<0.001$ \\
\hline & $>800$ & 30.0 & & 30.0 & \\
\hline \multirow{2}{*}{$\begin{array}{l}\text { Hemoglobin } \\
(\mathrm{g} / \mathrm{dL})\end{array}$} & $<12$ & 90.2 & 0.254 & 94.7 & 0.159 \\
\hline & $\geq 12$ & 84.1 & & 86.5 & \\
\hline \multirow{2}{*}{$\begin{array}{l}\text { Platelet count }(x \\
\left.10^{3} \text { per } \mu \mathrm{L}\right)\end{array}$} & $\leq 400$ & 88.8 & 0.484 & 93.3 & 0.275 \\
\hline & $>400$ & 83.9 & & 77.8 & \\
\hline
\end{tabular}

Bolded values are statistically significant.

BMI, body mass index; FIGO, International Federation of Gynecology and

Obstetrics; LN, lymph node; LVS, lymphovascular space; RM, resection margin

WBC, white blood cell; ANC, absolute neutrophil count; ALC, absolute lymphocyte count; AMC, absolute monocyte count.

In our study, we found that AMC was more strongly prognostic, compared to LMR, and this finding is compatible with previous reports of breast
[29] and prostate [34] cancer. In a breast cancer study by Wen et al., AMC was identified as an independent prognostic parameter for OS through a multivariate analysis, whereas the prognostic value of LMR was not confirmed [29]. In addition, in a prostate cancer study by Shigeta et al., AMC, but not LMR, was identified as an independent prognostic factor for PFS and OS in a multivariate analysis [34]. Although we also observed the prognostic significance of AMC over LMR in our cohort, no available studies have focused on these factors in early-stage cervical cancers. However, in a study by Li et al. that included stage IIA-IVA cervical cancer (stage IIA: $20.3 \%$ of total), a multivariate analysis highlighted the significance of LMR as a surrogate marker for both PFS and OS but found no survival prognostic value of AMC [7]. It is too early to reach a conclusion regarding the inconsistent results between our study and those of the previous study by Li et al. Further studies are needed to validate the significance of AMC over LMR, or vice versa, in patients with earlyand advanced-stage cervical cancers.

Table 3. Relationships of demographic, clinicopathologic, and laboratory characteristics with progression-free survival in 233 patients with cervical cancer.

\begin{tabular}{|c|c|c|c|c|}
\hline \multirow[b]{2}{*}{ Variable } & \multicolumn{2}{|l|}{ Univariate } & \multicolumn{2}{|l|}{ Multivariate } \\
\hline & HR (95\% CI) & $P$-value & $\operatorname{HR}(95 \%$ CI) & $P$-value \\
\hline $\begin{array}{l}\text { BMI }\left(\mathrm{kg} / \mathrm{m}^{2}\right)(\leq 25 \mathrm{vs} \text {. } \\
>25)\end{array}$ & $\begin{array}{l}2.08 \\
(0.90-4.81)\end{array}$ & 0.088 & & \\
\hline $\begin{array}{l}\text { Age (years) ( } \leq 65 \text { vs. } \\
>65)\end{array}$ & $\begin{array}{l}2.60 \\
(1.02-6.65)\end{array}$ & 0.046 & & \\
\hline $\begin{array}{l}\text { Histology (Squamous } \\
\text { vs. non-squamous) }\end{array}$ & $\begin{array}{l}1.57 \\
(0.64-3.84)\end{array}$ & 0.327 & & \\
\hline $\begin{array}{l}\text { Histologic grade (1 vs. } \\
2-3 \text { ) }\end{array}$ & $\begin{array}{l}3.05 \\
(1.03-9.03)\end{array}$ & 0.044 & & \\
\hline $\begin{array}{l}\text { Stage (FIGO) (IB1 vs. } \\
\text { IB2-IIA) }\end{array}$ & $\begin{array}{l}2.24 \\
(0.97-5.19)\end{array}$ & 0.060 & & \\
\hline $\begin{array}{l}\text { Size }(\mathrm{cm})(\leq 2.6 \mathrm{vs} . \\
>2.6)\end{array}$ & $\begin{array}{l}4.91 \\
(1.66-14.51)\end{array}$ & 0.004 & $\begin{array}{l}5.41 \\
(1.81-16.15)\end{array}$ & 0.003 \\
\hline $\begin{array}{l}\text { LN invasion (negative } \\
\text { vs. positive) }\end{array}$ & $\begin{array}{l}1.67 \\
(0.66-4.28)\end{array}$ & 0.282 & & \\
\hline $\begin{array}{l}\text { LVS invasion } \\
\text { (negative vs. positive) }\end{array}$ & $\begin{array}{l}1.26 \\
(0.53-3.01)\end{array}$ & 0.600 & & \\
\hline $\begin{array}{l}\text { RM involvement } \\
\text { (negative vs. positive) }\end{array}$ & $\begin{array}{l}2.75 \\
(0.64-11.77)\end{array}$ & 0.173 & & \\
\hline $\begin{array}{l}\text { WBC }(\text { per } \mu \mathrm{L})(\leq 11000 \\
\text { vs. }>11000)\end{array}$ & $\begin{array}{l}5.55 \\
(1.64-18.79)\end{array}$ & 0.006 & & \\
\hline $\begin{array}{l}\text { ANC }(\text { per } \mu \mathrm{L})(\leq 7700 \\
\text { vs. }>7700)\end{array}$ & $\begin{array}{l}3.28 \\
(0.76-14.06)\end{array}$ & 0.110 & & \\
\hline $\begin{array}{l}\text { ALC }(\text { per } \mu \mathrm{L})(<1000 \\
\text { vs. } \leq 1000)\end{array}$ & $\begin{array}{l}1.66 \\
(0.49-5.62)\end{array}$ & 0.415 & & \\
\hline $\begin{array}{l}\mathrm{AMC}(\text { per } \mu \mathrm{L})(\leq 800 \\
\text { vs. }>800)\end{array}$ & $\begin{array}{l}9.06 \\
(2.67-30.70)\end{array}$ & $<0.001$ & $\begin{array}{l}11.78 \\
(3.43-40.49)\end{array}$ & $<0.001$ \\
\hline $\begin{array}{l}\text { Hemoglobin }(\mathrm{g} / \mathrm{dL}) \\
(<12 \text { vs. } \geq 12)\end{array}$ & $\begin{array}{l}1.65 \\
(0.69-3.94)\end{array}$ & 0.259 & & \\
\hline $\begin{array}{l}\text { Platelet }\left(\times 10^{3} \text { per } \mu \mathrm{L}\right) \\
(\leq 400 \text { vs. }>400)\end{array}$ & $\begin{array}{l}1.67 \\
(0.39-7.16)\end{array}$ & 0.490 & & \\
\hline
\end{tabular}
( $\leq 400$ vs. $>400)$

Bolded values are statistically significant.

Hazard ratios were obtained using Cox's proportional hazards model.

HR, hazard ratio; CI, confidence interval; BMI, body mass index; FIGO, International Federation of Gynecology and Obstetrics; LN, lymph node; LVS, lymphovascular space; RM, resection margin; WBC, white blood cell; ANC, absolute neutrophil count; ALC, absolute lymphocyte count; AMC, absolute monocyte count. 
Table 4. Relationships of demographic, clinicopathologic, and laboratory characteristics with overall survival in 233 patients with cervical cancer.

\begin{tabular}{|c|c|c|c|c|}
\hline \multirow[b]{2}{*}{ Variable } & \multicolumn{2}{|l|}{ Univariate } & \multicolumn{2}{|l|}{ Multivariate } \\
\hline & $\mathrm{HR}(95 \% \mathrm{CI})$ & $P$-value & HR $(95 \% \mathrm{CI})$ & $P$-value \\
\hline BMI $\left(\mathrm{kg} / \mathrm{m}^{2}\right)(\leq 25$ vs. $>25)$ & $1.86(0.64-5.35)$ & 0.253 & & \\
\hline Age (years) $(\leq 65$ vs. $>65)$ & $3.98(1.32-12.00)$ & 0.014 & & \\
\hline Histology (Squamous vs. non-squamous) & $1.27(0.40-4.06)$ & 0.688 & & \\
\hline Histologic grade (1 vs. $2-3$ ) & $3.97(0.89-17.79)$ & 0.072 & & \\
\hline Stage (FIGO) (IB1 vs. IB2-IIA) & $3.82(1.32-11.09)$ & 0.014 & & \\
\hline Size $(\mathrm{cm})(\leq 2.6$ vs. $>2.6)$ & $6.33(1.42-28.31)$ & 0.016 & $5.27(1.15-24.23)$ & 0.033 \\
\hline LN invasion (negative vs. positive) & $3.47(1.20-9.99)$ & 0.021 & $3.90(1.17-12.96)$ & 0.027 \\
\hline LVS invasion (negative vs. positive) & $0.84(0.26-2.68)$ & 0.768 & & \\
\hline RM involvement (negative vs. positive) & $1.79(0.23-13.75)$ & 0.575 & & \\
\hline WBC $($ per $\mu \mathrm{L})(\leq 11000 \mu \mathrm{L}$ vs. $>11000)$ & $8.10(2.26-29.10)$ & 0.001 & & \\
\hline ANC $($ per $\mu \mathrm{L})(\leq 7700$ vs. $>7700)$ & $5.38(1.19-24.34)$ & 0.029 & & \\
\hline ALC $($ per $\mu \mathrm{L})(<1000$ vs. $\leq 1000)$ & $3.12(0.86-11.36)$ & 0.084 & & \\
\hline $\mathrm{AMC}($ per $\mu \mathrm{L})(\leq 800$ vs. $>800)$ & $12.90(3.54-46.95)$ & $<0.001$ & $23.29(5.40-100.38)$ & $<0.001$ \\
\hline Hemoglobin (g/dL) (<12 vs. $\geq 12)$ & $2.10(0.73-6.07)$ & 0.169 & & \\
\hline Platelet $\left(\times 10^{3}\right.$ per $\left.\mu \mathrm{L}\right)(\leq 400$ vs. $>400)$ & $2.27(0.50-10.33)$ & 0.288 & & \\
\hline
\end{tabular}

Bolded values are statistically significant.

Hazard ratios were obtained using Cox's proportional hazards model.

HR, hazard ratio; CI, confidence interval; BMI, body mass index; FIGO, International Federation of Gynecology and Obstetrics; LN, lymph node; LVS, lymphovascular space; $\mathrm{RM}$, resection margin; WBC, white blood cell; ANC, absolute neutrophil count; ALC, absolute lymphocyte count; AMC, absolute monocyte count.

Regarding pathologic variables, we identified tumor size as the strongest prognostic factor affecting PFS and OS in a multivariate analysis. Actually, the size of the tumor has been considered as a strong indicator of recurrence or death in early cervical cancer patients [5, 35-38]. However, the value of tumor size as a prognosticator remains controversial $[4,6,14,15,39-42]$. In addition, we also identified LN involvement as another strongest prognostic factor affecting OS. The value of $\mathrm{LN}$ involvement as an important prognostic factor for survival has been reported previously $[4,6,15,36-38,41,42]$. However, the prognostic role of $\mathrm{LN}$ involvement remains unresolved [5, 14, 35, 39, 40, 43].

The strength of the current study was the identification, for the first time, of AMC as an independent prognostic factor for survival in stage IB and IIA cervical cancer. Moreover, in this study, we evaluated the prognostic value of the AMC while considering the effects of various demographic, clinicopathologic, and laboratory parameters, including the NLR and LMR. However, we must note some limitations of the current study, including its retrospective nature and inclusion of a relatively small number of patients. In addition, we could not evaluate the role of the SCC antigen level, as we did not limit our study to squamous cell carcinoma. Furthermore, although we tried to avoid known confounders, some results may have been affected by the presence of coexisting systemic conditions.

In conclusion, monocytosis provides important information that could be used to accurately predict future progression or death in patients with stage IB and IIA cervical cancer who have undergone standard surgical resection. In addition, we identified the AMC, but not LMR, as a significant prognostic factor in our cohort. However, large-scale investigations are needed before this effective and convenient prognostic factor can be applied for risk stratification. Moreover, as only patients with stage IB and IIA cervical cancer were included in this study, additional studies of more advanced-stage cervical cancers are required.

\section{Acknowledgements}

This research was supported by the Bio \& Medical Technology Development Program of the NRF funded by the Korean government, MSIP (2016M3A9E8942067).

\section{Competing Interests}

The authors have declared that no competing interest exists.

\section{References}

1. Torre LA, Bray F, Siegel RL, Ferlay J, Lortet-Tieulent J, Jemal A. Global cancer statistics, 2012. CA. 2015;65:87-108.

2. Moore KN, Java JJ, Slaughter KN, Rose PG, Lanciano R, DiSilvestro PA, et al. Is age a prognostic biomarker for survival among women with locally advanced cervical cancer treated with chemoradiation? An NRG Oncology/Gynecologic Oncology Group ancillary data analysis. Gynecol Oncol. 2016;143:294-301.

3. Takeda N, Sakuragi N, Takeda M, Okamoto K, Kuwabara M, Negishi H, et al. Multivariate analysis of histopathologic prognostic factors for invasive cervical cancer treated with radical hysterectomy and systematic retroperitoneal lymphadenectomy. Acta obstetricia et gynecologica Scandinavica. 2002;81:1144-51.

4. Yang SS, Gao Y, Wang DY, Xia BR, Liu YD, Qin Y, et al. Overexpression of eukaryotic initiation factor 5A2 (EIF5A2) is associated with cancer progression and poor prognosis in patients with early-stage cervical cancer. Histopathology. 2016;69:276-87.

5. Kawano M, Mabuchi S, Matsumoto Y, Sasano T, Takahashi R, Kuroda H, et al. Prognostic Significance of Pretreatment Thrombocytosis in Cervical Cancer Patients Treated With Definitive Radiotherapy. Int J Gynecol Cancer. 2015;25:1656-62. 
6. Jiamset I, Hanprasertpong J. Impact of diabetes mellitus on oncological outcomes after radical hysterectomy for early stage cervical cancer. J Gynecol Oncol. 2016;27:e28.

7. Li SW, Yuan W, Zhao B, He ZK, Guo X, Xia WX, et al. Positive effect of HPV status on prognostic value of blood lymphocyte-to-monocyte ratio in advanced cervical carcinoma. Cancer cell international. 2016;16:54.

8. Chen L, Zhang F, Sheng XG, Zhang SQ. Decreased pretreatment lymphocyte/monocyte ratio is associated with poor prognosis in stage Ib1-IIa cervical cancer patients who undergo radical surgery. Onco Targets Ther. 2015;8:1355-62.

9. Sun F, Xiao L, Jang XX, Xiong Y, Li Q, Yue XJ, et al. TRPV6 is a prognostic marker in early-stage cervical squamous cell carcinoma. Tumour biology. 2016.

10. Onal C, Guler OC, Yildirim BA. Prognostic Use of Pretreatment Hematologic Parameters in Patients Receiving Definitive Chemoradiotherapy for Cervical Cancer. Int J Gynecol Cancer. 2016;26:1169-75.

11. Cho Y, Kim KH, Yoon HI, Kim GE, Kim YB. Tumor-related leukocytosis is associated with poor radiation response and clinical outcome in uterine cervical cancer patients. Annals of oncology. 2016;27:2067-74.

12. Mabuchi S, Matsumoto Y, Kawano M, Minami K, Seo Y, Sasano T, et al. Uterine cervical cancer displaying tumor-related leukocytosis: a distinct clinical entity with radioresistant feature. J Natl Cancer Inst. 2014;106.

13. Lee YY, Choi CH, Sung CO, Do IG, Huh S, Song T, et al. Prognostic value of pre-treatment circulating monocyte count in patients with cervical cancer: comparison with SCC-Ag level. Gynecol Oncol. 2012;124:92-7.

14. Wang YY, Bai ZL, He JL, Yang Y, Zhao R, Hai P, et al. Prognostic Value of Neutrophil-Related Factors in Locally Advanced Cervical Squamous Cell Carcinoma Patients Treated with Cisplatin-Based Concurrent Chemoradiotherapy. Disease markers. 2016;2016:3740794.

15. Zhang Y, Wang L, Liu Y, Wang S, Shang P, Gao Y, et al. Preoperative neutrophil-lymphocyte ratio before platelet-lymphocyte ratio predicts clinical outcome in patients with cervical cancer treated with initial radical surgery. Int J Gynecol Cancer. 2014;24:1319-25.

16. Chen L, Zhang F, Sheng XG, Zhang SQ, Chen YT, Liu BW. Peripheral platelet/lymphocyte ratio predicts lymph node metastasis and acts as a superior prognostic factor for cervical cancer when combined with neutrophil: Lymphocyte. Medicine. 2016;95:e4381.

17. Landoni F, Sartori E, Maggino T, Zola P, Zanagnolo V, Cosio S, et al. Is there a role for postoperative treatment in patients with stage Ib2-IIb cervical cancer treated with neo-adjuvant chemotherapy and radical surgery? An Italian multicenter retrospective study. Gynecol Oncol. 2014;132:611-7.

18. Colombo N, Carinelli S, Colombo A, Marini C, Rollo D, Sessa C. Cervical cancer: ESMO Clinical Practice Guidelines for diagnosis, treatment and follow-up. Annals of oncology. 2012;23 Suppl 7:vii27-32.

19. Moghadamyeghaneh Z, Hanna MH, Carmichael JC, Mills SD, Pigazzi A, Stamos MJ. Preoperative Leukocytosis in Colorectal Cancer Patients. Journal of the American College of Surgeons. 2015;221:207-14

20. Ozcan C, Telli O, Ozturk E, Suer E, Gokce MI, Gulpinar O, et al. The prognostic significance of preoperative leukocytosis and neutrophil-to-lymphocyte ratio in patients who underwent radical cystectomy for bladder cancer. Canadian Urological Association journal. 2015;9:E789-94.

21. Dale DC. Chapter 65. Neutropenia and Neutrophilia. In: Lichtman MA, Kipps TJ, Seligsohn U, Kaushansky K, Prchal JT, editors. Williams Hematology, 8e. New York, NY: The McGraw-Hill Companies; 2010.

22. Morotti A, Marini S, Jessel MJ, Schwab K, Kourkoulis C, Ayres AM, et al. Lymphopenia, Infectious Complications, and Outcome in Spontaneous Intracerebral Hemorrhage. Neurocritical care. 2016.

23. Lichtman MA. Chapter 71. Monocytosis and Monocytopenia. In: Lichtman MA, Kipps TJ, Seligsohn U, Kaushansky K, Prchal JT, editors. Williams Hematology, 8e. New York, NY: The McGraw-Hill Companies; 2010.

24. Chen JJ, Lin YC, Yao PL, Yuan A, Chen HY, Shun CT, et al. Tumor-associated macrophages: the double-edged sword in cancer progression. Journal of clinical oncology. 2005;23:953-64.

25. Friedman DR, Sibley AB, Owzar K, Chaffee KG, Slager S, Kay NE, et al. Relationship of blood monocytes with chronic lymphocytic leukemia aggressiveness and outcomes: a multi-institutional study. American journal of hematology. 2016;91:687-91.

26. Chen Y, Neelapu S, Feng L, Bi W, Yang TH, Wang M, et al. Prognostic significance of baseline peripheral absolute neutrophil, monocyte and serum beta2-microglobulin level in patients with diffuse large b-cell lymphoma: a new prognostic model. British journal of haematology. 2016;175:290-9.

27. Elias EG, Leuchten JM, Buda BS, Brown SD. Prognostic value of initial mononucleated cell percentages in patients with epidermoid carcinoma of the head and neck. American journal of surgery. 1986;152:487-90.

28. Go SI, Kim RB, Song HN, Kang MH, Lee US, Choi HJ, et al. Prognostic significance of the absolute monocyte counts in lung cancer patients with venous thromboembolism. Tumour biology. 2015;36:7631-9.

29. Wen J, Ye F, Huang X, Li S, Yang L, Xiao X, et al. Prognostic Significance of Preoperative Circulating Monocyte Count in Patients With Breast Cancer: Based on a Large Cohort Study. Medicine. 2015;94:e2266.

30. Sasaki A, Iwashita Y, Shibata K, Matsumoto T, Ohta M, Kitano S. Prognostic value of preoperative peripheral blood monocyte count in patients with hepatocellular carcinoma. Surgery. 2006;139:755-64.

31. Bruckner HW, Lavin PT, Plaxe SC, Storch JA, Livstone EM. Absolute granulocyte, lymphocyte, and moncyte counts. Useful determinants of prognosis for patients with metastatic cancer of the stomach. JAMA. 1982;247:1004-6.

32. Leitch EF, Chakrabarti M, Crozier JE, McKee RF, Anderson JH, Horgan PG, et al. Comparison of the prognostic value of selected markers of the systemic inflammatory response in patients with colorectal cancer. British journal of cancer. 2007;97:1266-70.

33. Schmidt H, Bastholt L, Geertsen P, Christensen IJ, Larsen S, Gehl J, et al. Elevated neutrophil and monocyte counts in peripheral blood are associated with poor survival in patients with metastatic melanoma: a prognostic model. British journal of cancer. 2005;93:273-8.

34. Shigeta K, Kosaka T, Kitano S, Yasumizu Y, Miyazaki Y, Mizuno R, et al. High Absolute Monocyte Count Predicts Poor Clinical Outcome in Patients with Castration-Resistant Prostate Cancer Treated with Docetaxel Chemotherapy. Annals of surgical oncology. 2016;23:4115-22.

35. Haraga J, Nakamura K, Omichi C, Nishida T, Haruma T, Kusumoto T, et al. Pretreatment prognostic nutritional index is a significant predictor of prognosis in patients with cervical cancer treated with concurrent chemoradiotherapy. Molecular and clinical oncology. 2016;5:567-74.

36. Memarzadeh S, Natarajan S, Dandade DP, Ostrzega N, Saber PA, Busuttil A, et al. Lymphovascular and perineural invasion in the parametria: a prognostic factor for early-stage cervical cancer. Obstet Gynecol. 2003;102:612-9.

37. Li X, Tan C, Zhang W, Zhou J, Wang Z, Wang S, et al. Correlation Between Platelet and Hemoglobin Levels and Pathological Characteristics and Prognosis of Early-Stage Squamous Cervical Carcinoma. Med Sci Monit. 2015;21:3921-8

38. Nanthamongkolkul K, Hanprasertpong J. Longer waiting times for early stage cervical cancer patients undergoing radical hysterectomy are associated with diminished long-term overall survival. J Gynecol Oncol. 2015;26:262-9.

39. Azizmohammadi S, Safari A, Azizmohammadi S, Kaghazian M, Sadrkhanlo M, Yahaghi E, et al. Molecular identification of miR-145 and miR-9 expression level as prognostic biomarkers for early-stage cervical cancer detection. QJM. 2017;110:11-5.

40. Qiu JT, Abdullah NA, Chou HH, Lin CT, Jung SM, Wang CC, et al. Outcomes and prognosis of patients with recurrent cervical cancer after radical hysterectomy. Gynecol Oncol. 2012;127:472-7.

41. Park JW, Bae JW. Prognostic significance of positive lymph node number in early cervical cancer. Molecular and clinical oncology. 2016;4:1052-6.

42. Zhao K, Deng H, Qin Y, Liao W, Liang W. Prognostic significance of pretreatment plasma fibrinogen and platelet levels in patients with early-stage cervical cancer. Gynecol Obstet Invest. 2015;79:25-33.

43. Sun F, Xiong Y, Zhou XH, Li Q, Xiao L, Long P, et al. Acylglycerol kinase is over-expressed in early-stage cervical squamous cell cancer and predicts poor prognosis. Tumour biology. 2016;37:6729-36. 